\title{
On the Mechanism of the Permeation of Ions Through Paint Films
}

\author{
Yasushi Sato \\ Railway Technical Research Institute, Japanese National Railways, Kunitachi, Tokyo
}

Temperature characteristics of direct current conductivity of polyvinyl acetate and epoxy resin paint films in $3 \%$ sodium chloride solution were found to be altered markedly at the border of the glass transition temperature of paint films. As direct current conductivity of paint films in electrolytic solutions had been proved to be entirely ionic, it was concluded that ions activatedly diffuse through paint films themselves rather than through pin-holes.

Alternative current conductivity of paint films in sodium chloride solution was established to be the sum of alternative conductivity of dry films and direct current conductivity owing to the diffusion of ions. Therefore, if the difference of permeability constant of ions among many paint films is much larger than the difference of dielectric constant and loss, ionic permeability which is the measure of the anti-corrosive property of paints must be able to be estimated by the measurements of $\tan \delta$ of painted steel panels in electrolytic solution as already suggested by Okamoto, Morozumi, and Yamashina. In order to demonstrate the significance of the $\tan \delta$ method, the values of $\tan \delta$ and direct current conductivity of about thirty kinds of painted steel panels in electrolytic solutions were compared each other. It was recognized that $\tan \delta$ kept pace with direct current conductivity as far as the values of $\tan \delta$ exceeded 0.1 .

\section{Introduction}

The author previously measured the self-diffusion coefficient of ions in paint films with radioisotopes and deduced from the results that ions activatedly diffuse through paint films themselves rather than through pin-poles ${ }^{1}$.

Temperature characteristics of various physical properties of amorphous polymers are altered markedly at the border of the glass transition temperature of polymers. If the above deduction is correct, temperature characteristics of ionic permeability of films should also be affected with the glass transition of paint films. On this aspect, in the present paper, temperature characteristics of ionic permeability of paint films were measured at a range of temperature including glass transition temperature in order to verify the above deduction.

\section{Experimental Method}

As it had been already verified that direct current conductivity of paint films in electrolytic solutions is entirely ionic ${ }^{1)}$, temperature characteristics of direct current conductivity of painted tin-plate panels in $3 \%$ sodium chloride solution was measured instead of the direct measurement of ionic permeability.

Unpigmented polyvinyl acetate and epoxy resin paints were examined. In the case of polyvinyl acetate, panels were coated three times at the intervals of 24 hours and then dried for 3 hours at $80^{\circ} \mathrm{C}$. In the case of epoxy resin, panels were also coated three times and were dried for 10 minutes at $70^{\circ} \mathrm{C}$ in each time, and when the last coating was finished panels were baked for 30 minutes at $100^{\circ} \mathrm{C}$.

Impedance of painted panels acquired steady values about ten days after immersion (Fig. 1-2). As the corrosion rate of tin-plate panel in sodium chloride solution is very small, deteriorations of paint films, for example blistering and peeling, did not appear, and so the values of impedance of coated panels are considered to be mainly affected with the swelling of paint films in sodium chloride solution. 


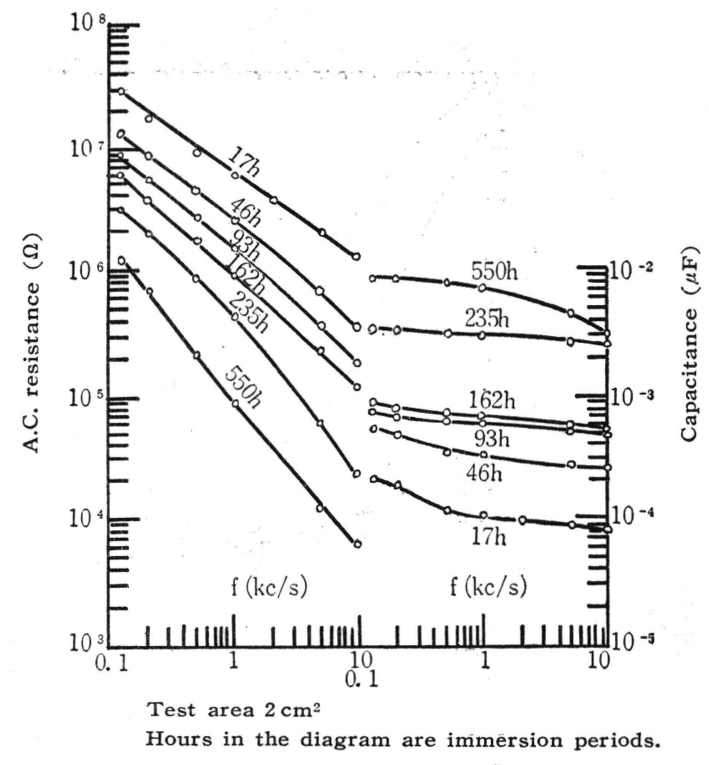

Fig. 1 Frequency characteristics of impedance of the test panel painted with polyvinyl acetate in sodium chloride solution

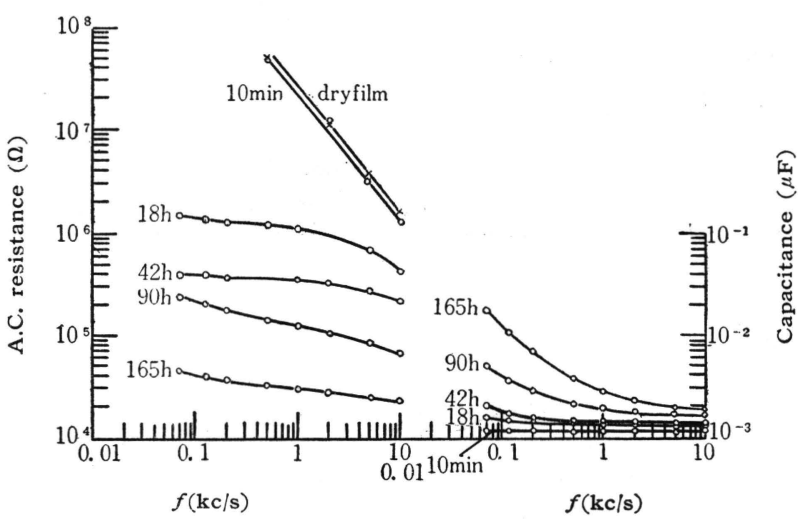

Test area $17 \mathrm{~cm}^{2}$

Hours in the diagram are immersion period.

Fig. 2 Frequency characteristics of impedance of the test panel painted with epoxy resin in sodium chloride solution
After the steady values of inpedance had been acquired, tempera turecharacteristics of conductance o panels were measured. Direct current conductance was measured by Bacon's $\operatorname{method}^{2)}$. Alternative current conductance was measured with the apparatus previously reported ${ }^{9}$.

The experimental temperature was limited to the ranges in which the conductance of panels returned to the original value gradually when the temperature fell to room temperature from the highest one for the experiments.

Impedance of dry paint films had been measured in mercury before panels were immersed in sodium chloride solution (Fig. 3 4).

Thermal expansion of dry films was measured with dilatometers in order to determine the glass transition temperature of paint films. The capacity of dilatometers was about $20 \mathrm{cc}$ and the volume of the tested films was about $11 \mathrm{cc}$. Inside diameter of the capillary tubes of diatometers was about $2 \mathrm{~mm}$. Accuracy of the measurements of temperature was $0.1^{\circ} \mathrm{C}$ and of the height of mercury column was $0.01 \mathrm{~mm}$.

In these experiments, the velocity of raising temperature was maintained at $0.42-0.50^{\circ} \mathrm{C} / \mathrm{min}$. in the use of the

apparatus being similar to the Kuroda's one ${ }^{3)}$.

\section{Results and Discussions}

Considering from the experimental results in Fig. 7, polyvinyl acetate is in glassy state below $17^{\circ} \mathrm{C}$, in transitional state between $17^{\circ} \mathrm{C}$ and $29^{\circ} \mathrm{C}$, and in viscous fluid state above $29^{\circ} \mathrm{C}$, and epoxy resin is in glassy bellow $60^{\circ} \mathrm{C}$, in transitional between 60 and $71^{\circ} \mathrm{C}$ and in viscous fluid state above $71^{\circ} \mathrm{C}$.

Temperature characteristics of direct current conductance of paint films in sodium chloride solution obviously correspond to the experimental results of thermal expansion (Fig. $5 \& 6$ ). Therefore, the deduction described at the outset was verified. When the experimental results about paint films in sodium chloride solution are compared with the ones by dilatometers about dry films, the influence of wat ermust generally be taken into consideration, but from the results of above experiments the plasticizing 
Temp. ${ }^{\circ} \mathrm{C}$

Temp. ${ }^{\circ} \mathrm{C}$

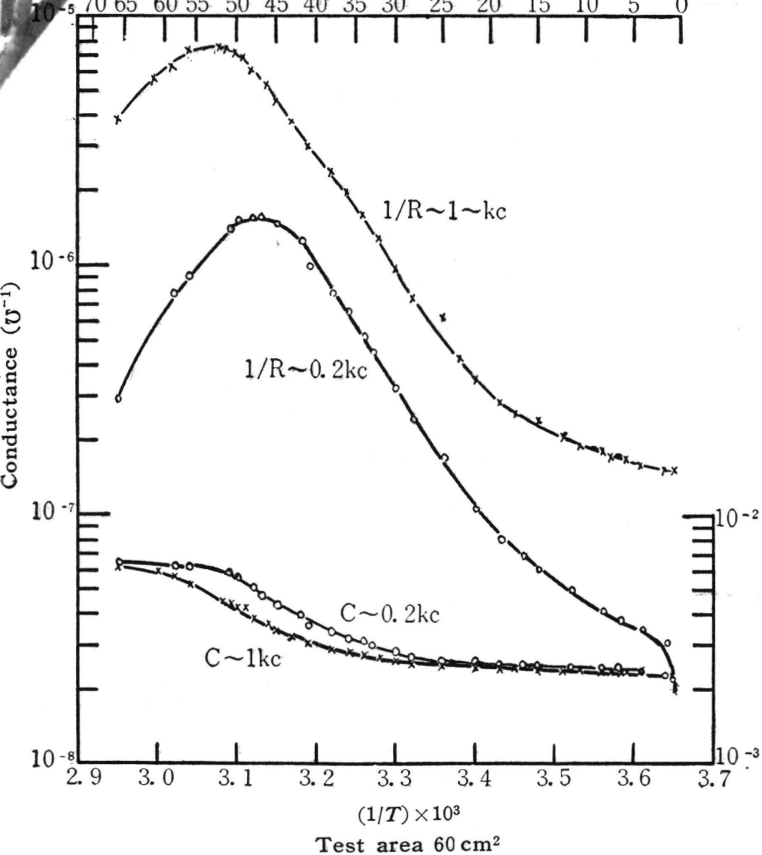

Fig. 3 Temperature characteristics of impedance of the dry test panel painted with polyvinyl acetate

Temp. ${ }^{\circ} \mathrm{C}$

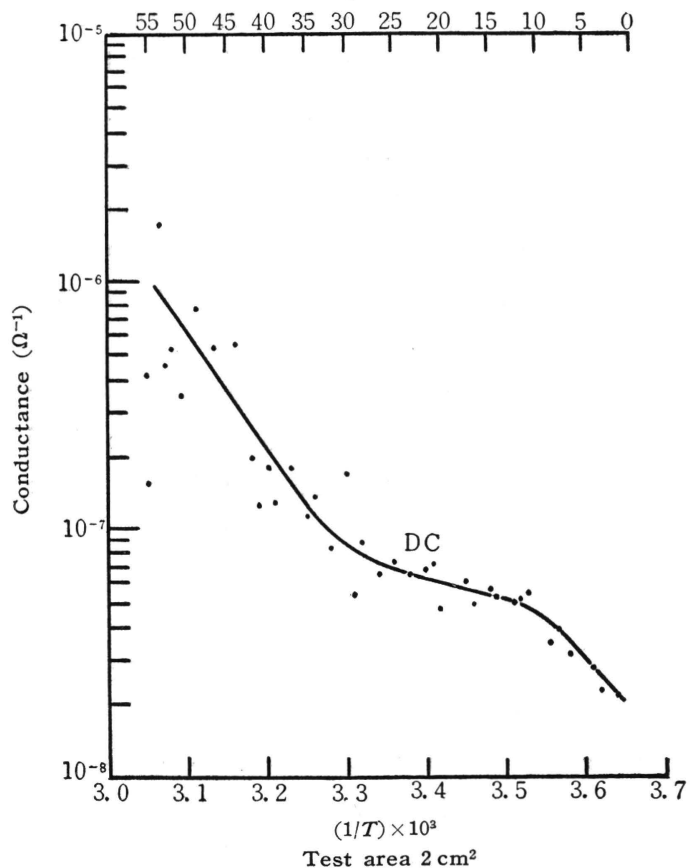

Fig. 5-(1) Temperature characteristics of conductance of the test panel painted with polyvinyl acetate in sodium chloride solution (D.C.)
$95908580757065605550454035 \quad 302520 \quad 15$

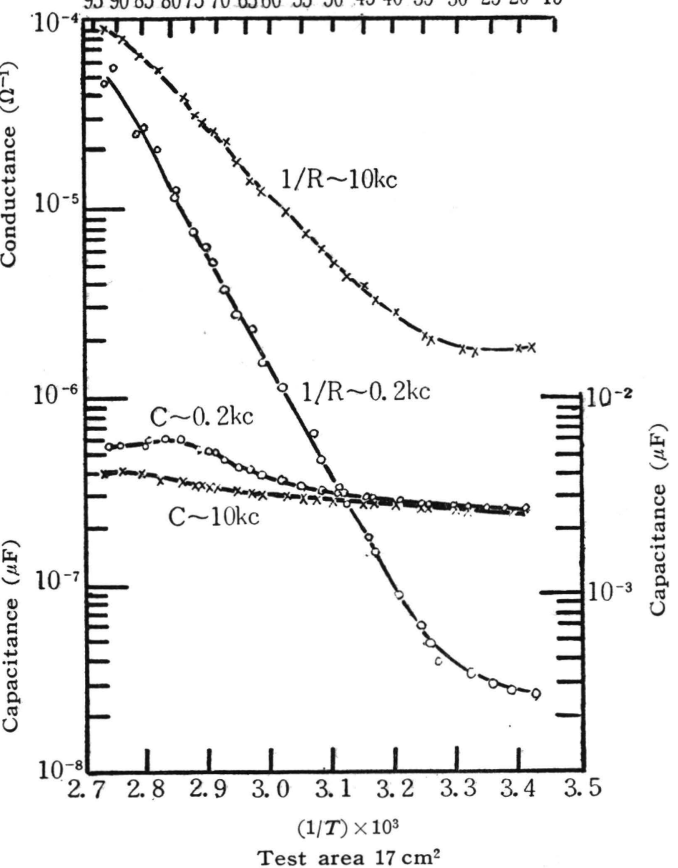

Fig. 4 Temperature characteristics of impedance of the dry test panel painted with epoxy resin

Temp. ${ }^{\circ} \mathrm{C}$

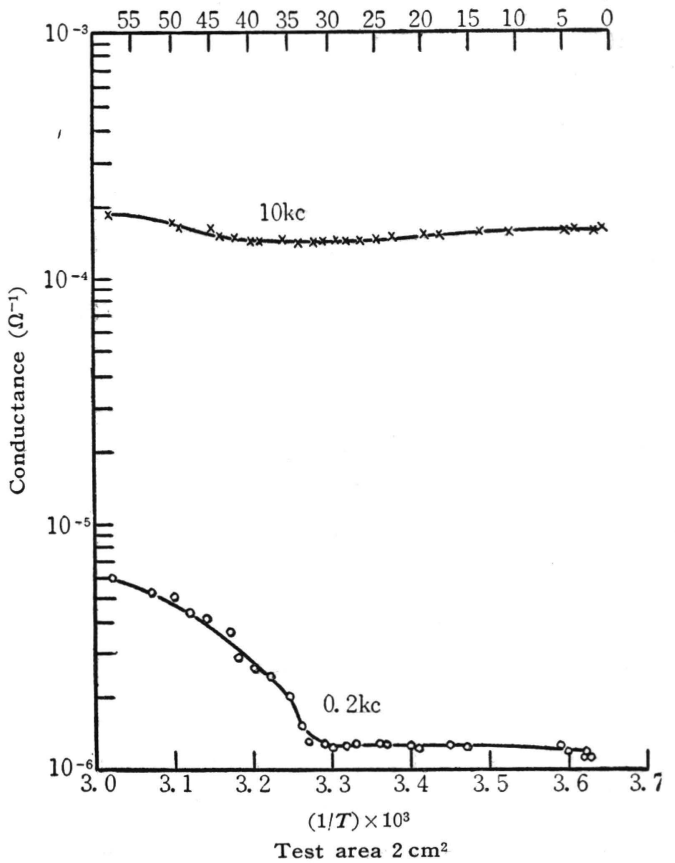

Fig. 5-(2) Temperature characteristics of conductance of the test panel painted with polyvinyl acetate in sodium chloride solution (A.C.) 
Temp. ${ }^{\circ} \mathrm{C}$

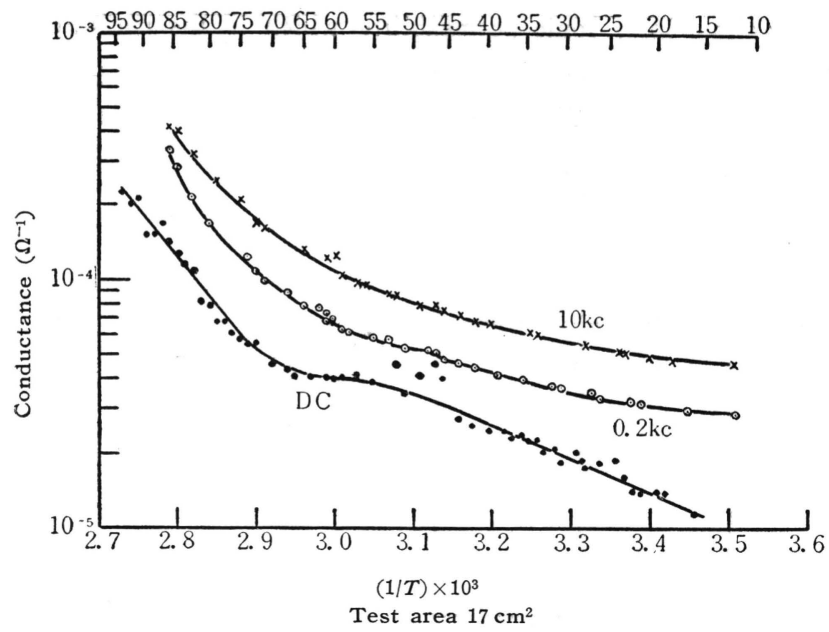

Fig. 6 Temperature characteristics of conductance of the test panel painted with epoxy resin in sodium chloride solution

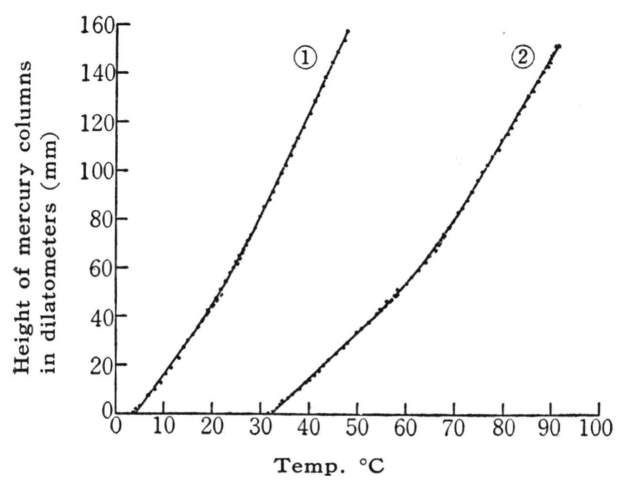

(1) Polyvinyl acetate

(2) Epoxy resin

Fig. 7 Thermal expansion of polyvinyl acetate and epoxy resin paint films action of water seemed to be slight. Herwig $^{4}$ had described the similar view.

Activation energy of direct current conductance $(\mathrm{kcal} / \mathrm{mol})$ is 16 (below $17^{\circ} \mathrm{C}$ ), 21 (above $29^{\circ} \mathrm{C}$ ) in the case of polyvinyl acetate, and is 6.6 (below $60^{\circ} \mathrm{C}$ ), 18 (above $71^{\circ} \mathrm{C}$ ) in the case of epoxy resin. But the value of activation energy in polyvinyl acetate above $29^{\circ} \mathrm{C}$ is not certain, because the measured values of conductance were scattered about. The value obtained below $17^{\circ} \mathrm{C}$ is coincident with the one reported by $\mathrm{Herwig}^{4}$ about direct current conductivity of dry polyvinyl acetate.

Movement of ions and protons are said to be a main part of direct current conductivity of dry organic polymers ${ }^{4), 5)}$. Experimental results described above, can be explained consistently by the fact that activated diffusion of sodium ion and chloride ion through films is a main part of direct current conductivity of paint films in sodium chloride solution.

Meares ${ }^{6)}$ reported that activation energy (kcal/ mol) of diffusion of gases through polyvinyl acetate films was $4.2-11.4$ (below $17^{\circ} \mathrm{C}$ ), $0-8.0$ (between $17^{\circ} \mathrm{C}$ and $26^{\circ} \mathrm{C}$ ), $5.4-16.5$ (above $26^{\circ} \mathrm{C}$ ). The results are quite similar to the ones about the direct current conductance of paint films in sodium chloride solution, therefore, the mechanism of diffusion of gases and ions are guessed to be identical.

$M{ }^{7} e^{7)}$ reported that many fine isolated droplets of water had been observed by phase-contrast microscope in paint films dipped in sodium chloride solution for several hours. As long as the distribution of water droplets is not dense, probably ions can scarecely diffuse from one droplet to another through the intervening polymer, but after the long contact with water, the distribution becomes dense and ions will diffuse more easily.

Supposing we have the model like this, temperature and frequency characteristics of alternative current conductivity of paint films in sodium chloride solution must be at first almost the same as the ones of dry films and after films are in contact with water for a sufficient time the effect of direct current conductivity owing to the diffusion of ions must be appreciable.

Experimental results in Fig. 1-6 agree well with the above description. Temperature and frequency characteristics of alternative current conductance of paint films in sodium chloride solution were the sum of the characteristics of alternative current conductance of dry films and direct current conductance owing to the diffusion of ions. 
Consequently, if the difference of ionic permeability constant among many paint films is much larger than the difference of dielectric constant and loss, ionic permeability which is the measure of the anti-corrosive property of paints must be able to be estimated by the measurement of $\tan \delta$ of painted steel panels in electrolytic solution as already suggested by Okamoto, Morozumi, and Yamashina ${ }^{8}$.

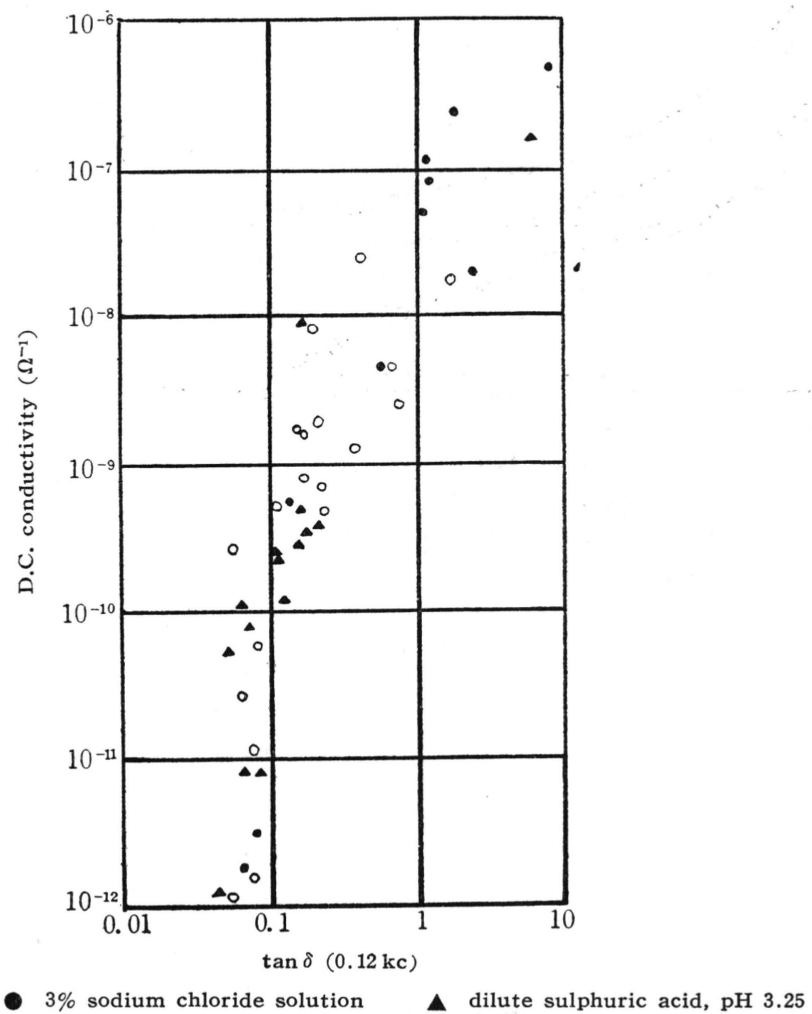

$\bigcirc$ tap water

- $3 \%$ sodium chloride solution

A dilute sulphuric acid, $\mathrm{pH} 3.25$

Fig. 8 D.C. conductivity and $\tan \delta$ of painted steel panels in electrolytic solution

In Fig. 8 direct current conductivity and $\tan \delta$ of many painted steel panels in electrolytic solution are compared. The tested paints contain oil paints, long oil alkyd resin paints, oil modified phenol resin paints, alkyl phenol resin paints, polyvinyl chloride resin paints, epoxy resin paints, polyurethane resin paints, cumarone-indene resin paints, coal tar enamels and epoxy coal tar enamels. It was observed that $\tan \delta$ kept pace with direct current conductivity as far as the value of $\tan \delta$ exceeded 0.1 . Accordingly $\tan \delta$ is qualified to be the measure of ionic permeability of paint films.

The anti-corrosive property estimated by $\tan \delta$ method has already been proved to be coincident with the results of outdoor exposure test ${ }^{9}$ and in this paper the physical meaning of this method is demonstrated.

(Received Mar. 4, 1961)

\section{Literature :}

1) Y. Sato, This Journal 28, E 224 (1960).

2) R.C. Bacon, J.J. Smith, F.M. Rugg, Ind. Eng. Chem., 40, 161 (1948).

3) T. Kuroda, Busseiron-Kenkyu 81, 113 (1955).

4) H.U. Herwig, E. Jenckel, Z. Elektrochem., 63, 360 (1959).

5) C.P. Smyth, "Dielectric Behaviour and Structure", Mc-Graw Hill ,N.Y. (1955).

6) P. Meares, J. Amer. Chem. Soc., 76, 3415 (1954).

7) J.E.O. Mayne, J. Oil Colour Chem. Assoc., 40, 183 (1957).

8) G. Okamoto, T. Morozumi, T. Yamashina, J. Chem: Soc. Japan, Ind. Ed., 61, 291 (1958).

9) Y. Sato, This Journal 26, E-200 (1958), 28, E 302 (1960). 